\title{
Gas turbine intake air hybrid cooling systems and their rational designing
}

\author{
Mykola Radchenko $^{1 *}$, Andrii Radchenko ${ }^{1}$, Dariusz Mikielewicz ${ }^{2}$, Krzysztof Kosowski $^{2}$, Serhiy Kantor $^{1}$ and Ivan \\ Kalinichenko ${ }^{1}$ \\ ${ }^{1}$ Admiral Makarov National University of Shipbuilding, 9 Heroes of Ukraine Avenue, Mykolayiv, Ukraine \\ ${ }^{2}$ Gdańsk University of Technology, 11/12 Gabriela Narutowicza Street, 80-233 Gdansk, Poland
}

\begin{abstract}
The general trend to improve the fuel efficiency of gas turbines (GT) at increased ambient temperatures is turbine intake air cooling (TIAC) by exhaust heat recovery chillers The high efficiency absorption lithium-bromide chillers (ACh) of a simple cycle are the most widely used, but they are not able to cool intake air lower than $15^{\circ} \mathrm{C}$ because of a chilled water temperature of about $7^{\circ} \mathrm{C}$. A two-stage hybrid absorption-ejector chillers (AECh) were developed with ejector chiller as a low temperature stage to provide deep air cooling to $10^{\circ} \mathrm{C}$ and lower. A novel trend in TIAC by two-stage air cooling in chillers of hybrid type has been proposed to provide about $50 \%$ higher annual fuel saving in temperate climatic conditions as compared with ACh cooling. The advanced methodology to design and rational distribute the cooling capacity of TIAC systems that provides a closed to maximum annual fuel reduction without oversizing was developed.
\end{abstract}

\section{Introduction}

The efficiency of gas turbines (GT) decreases with arising the ambient air temperature at their inlet $[1,2]$. The general trend to improve the fuel efficiency of GT at increased ambient air temperatures is turbine intake air cooling (TIAC) by exhaust heat recovery chillers [3]. A reduction of the chiller sizes with maximum annual fuel saving is possible due to rational design cooling capacity excluding oversizing $[4,5]$ and its rational distribution with small deviation of current loads from a design value $[6,7]$. In order to realize this the overall band of current cooling loads is to be divided into two ranges: the first unstable load range, following the fluctuations of current loads (thermal "turbulences"), and the second range of comparatively stable loads ("laminarized" thermal load range). The cooling capacity of the chillers is to be designed to cover the thermal "turbulences" by the absorption lithiumbromide chiller $(\mathrm{ACh})$ chillers with a high coefficient of performance (COP) not effected by load fluctuations considerably [8]. The further air subcooling takes place within the comparatively stable "laminarized" thermal load range) and can be covered by ejector chiller (ECh) as the most simple in design and cheapest but considerably effected by load changes [9]. The application of such hybrid absorption-ejector chiller (AECh) enables to cover actual loading in two-stage air cooler with boost high temperature water stage and low temperature refrigerant stage [10].

The purpose of the study is to develop the advanced hybrid TIAC systems and the improved methodology of their designing with rational distribution of the overall design cooling capacity between unstable ("turbulent") thermal load range for ambient air precooling in the boost high temperature stage of the air cooler (AC) by ACh and a stable ("laminarized") load range for further air subcooling to the target temperature in the low temperature stage by ECh that provides practically twice reduction of a design boost thermal load and about $50 \%$ higher annual fuel saving as compared with ACh gained due to applications of TIAC systems with hybrid AECh.

\section{Literature review}

In a number of investigations the combustion engine intake air cooling (EIAC) including TIAC is considered as subtechnologies for combined cooling, heating and power (CCHP) [11], or trigeneration [12,13]. A lot of researches are focused to improve the performance of air cooling systems by intensification of heat transfer in evaporators and condensers [14].

The technical innovations in waste heat recovery $[15,16]$ including transport application $[17,18]$ might be successfully applied in TIAC: two-stage intake air cooling [10], deep exhaust heat utilization [19, 20]. The heat potential for converting in refrigeration can be increased due to low-temperature condensation [21, 22].

Advanced methods as ANSIS [23] and statistical methods for processing monitoring data can be used for optimizing the cooling loads according site climatic conditions [24, 25] and along ship voyages [26]. The sinusoidal curve was proposed for daily thermal load fluctuations [27] to match current cooling demands.

\footnotetext{
* Corresponding author: nirad50@gmail.com
} 
Practically all the typical design methods [28, 29] issue from the assumption of a design cooling capacity to cover maximum cooling needs over the full range of yearly operating conditions, that inevitable leads to considerable cooling system oversizing and requires to define a correct design cooling load excluding overestimation.

\section{Research methodology}

A reduction of the chillers design cooling capacity is possible by determining its rational value to provide closed to maximum annual fuel saving as the first step of the methodology for designing the TIAC system and further distribution of the available cooling capacity in response to the current demands as the second step.

The annual fuel saving $\Sigma B_{e}$ of the GT due to inlet air cooling is assumed as a criterion to determine a rational design cooling capacity $Q_{0}$ of the TIAC system. With this the current fuel reduction $B_{e}$ have been summarized over the year:

$$
\Sigma B_{e}=\sum\left(\Delta t_{a} \cdot \tau\right) \cdot b_{e t} \cdot N_{e} \cdot 10^{-3}, \mathrm{t},
$$

where: $\Delta t_{a}=t_{a m b}-t_{a 2}-$ current intake air temperature drop, $\mathrm{K}$ or ${ }^{\circ} \mathrm{C}$; $t_{a m b}$ and $t_{a 2}$ - ambient air and air temperature at the air cooler outlet, $\mathrm{K}$ or ${ }^{\circ} \mathrm{C} ; N_{e}$ - turbine power output, $\mathrm{kW} ; \tau$ - time interval, $\mathrm{h} ; b_{e t}-$ specific fuel reduction for $1 \mathrm{~K}\left(1^{\circ} \mathrm{C}\right)$ air temperature drop, assumed $0.7 \mathrm{~g} /(\mathrm{kWh} \cdot \mathrm{K})$ for UGT10000 [30].

It is preferably to analyze the fuel reduction in dependence on specific cooling capacity $q_{0}$ as the overall its value $Q_{0}$ referred to air mass flow rate $G_{a}=1 \mathrm{~kg} / \mathrm{s}$ :

$$
q_{0}=Q_{0} / G_{a} \text { or } q_{0}=\xi \cdot c_{m a} \mathrm{~kW} /(\mathrm{kg} / \mathrm{s}) \text { or } \mathrm{kJ} / \mathrm{kg},
$$

where: $\xi$ - specific heat ratio; $c_{m a}-$ moist air specific heat, $\mathrm{kJ} /(\mathrm{kg} \cdot \mathrm{K}$.

According to the method developed the fluctuations of the current effect in GT fuel reduction $B_{e}$ are considered by the rate of their annual increment $\sum B_{e}$ as relative annual fuel saving increment $\Sigma B_{e} / Q_{0}$ referred the cooling capacity needed. A such methodological approach makes it possible to increase the accuracy of the results due to excluding the approximation of the current changeable values of $B_{e}$. This is a principally novelty versus a generally accepted approach to cover the maximum current demands to reach the maximum annual value $\sum B_{e}$ that leads to oversizing.

There are two methods developed: the first - by using the annual fuel reduction $\sum B_{f}$ dependence on the design cooling capacity of the chiller to choose its rational value $Q_{0 \text { rat }}$, that provides closed to maximum annual fuel reduction $\sum B_{e}$, and the second - according to the maximum rate of annual fuel reduction $\sum B_{e}$ increment $\sum B_{e} / Q_{0}$ to choose optimum design cooling capacity $Q_{0 . o p t}$, that provides minimum sizes of the chiller and TIAC system (Fig.1,a).

The rational value of design cooling capacity $Q_{0 \text {.rat }}$, providing a closed to maximum annual fuel reduction $\sum B_{e}$ is associated with the second maximum rate of annual fuel reduction $\sum B_{e}$ increment within its range beyond the first maximum rate: $Q_{0}>Q_{0.0 p t}$ and $\sum B_{e}>\sum B_{e \text { opt }}$ accordingly. With this a relative parameter $\sum\left(B_{e}-B_{e . \text { opt }}\right) / Q_{0}$ is used as indicator to choose a rational value $Q_{0 \text {.rat }}$ (Fig.1,b).

The optimum $Q_{0 . \text { opt }}$ and rational $Q_{0 \text {.rat cooling }}$ capacities for $t_{a 2}=10,15$ and $20^{\circ} \mathrm{C}$ were calculated for temperate climatic conditions of Voznesensk, Nikolaev region, southern Ukraine, 2017 year (Fig. 1).
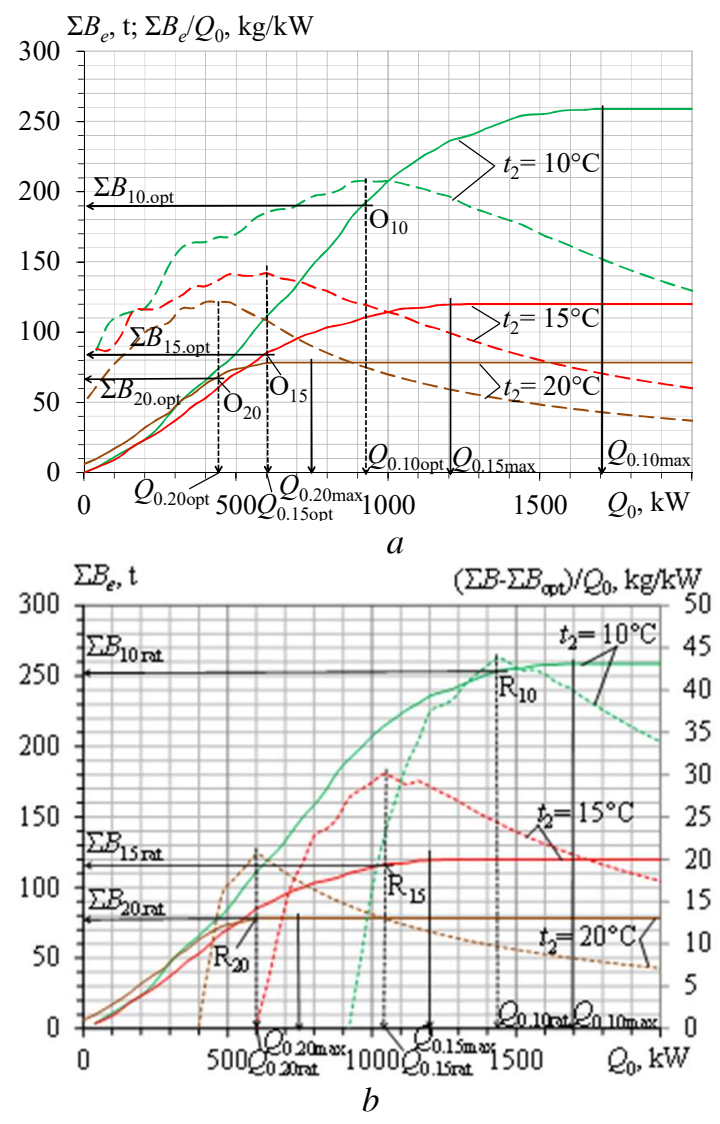

Fig.1. Annual fuel reduction $\sum B_{e}$ and its relative values $\sum B_{e} / \mathrm{Q}_{0}$ referred to design cooling capacity $Q_{0}$ over the whole range of $\sum B_{e}$ (a) and values $\sum\left(B_{e}-B_{e}\right.$.opt $) / Q_{0}$.beyond the optimum values of $\sum B_{e . o p t}$ and $Q_{0 . o p t}$ (b) for cooling ambient air to $t_{a 2}=10,15$ and $20^{\circ} \mathrm{C}$.

A maximum rate of annual fuel reduction $\sum B_{e}$ increment $\sum B_{e} / Q_{0}$. for $t_{a 2}=10^{\circ} \mathrm{C}$ takes place at the optimum design cooling capacity $Q_{0 \text {.opt }}$ of about $900 \mathrm{~kW}$ (Fig.1, a). A maximum rate of annual fuel reduction increment $\sum\left(B_{e}-B_{e \cdot \text { opt }}\right) / Q_{0}$ within the range beyond the value $\sum B_{f \cdot \mathrm{opt}}=190 \mathrm{t}$ corresponding to $Q_{0 . \mathrm{opt}}=900 \mathrm{~kW}$ takes place at the rational design cooling capacity $Q_{0 . \text { rat }}=1450 \mathrm{~kW}$ and provides annual fuel reduction $\sum B_{e \cdot \text { rat }}=250 \mathrm{t}$ that is very closed to its maximum value $260 \mathrm{t}$ but at a reduced design cooling capacity $Q_{0 \text {.rat }}=1450 \mathrm{~kW}$ less than $Q_{0 \text { max }}=1700 \mathrm{~kW}$ by $15 \%$.

The rational distribution of a design cooling capacity in response to the current thermal loads, as the second step of the methodology, requires comparing the available cooling capacity of the chillers with current cooling loads to determine the excessive available cooling capacity, revealed at the lowered current thermal loads on the air cooler (AC) at the inlet of GT, to cover the peaked current thermal loads.

Because of great uncertainty of unstable boost ("turbulent") load range magnitude its design value 
$q_{0 . \mathrm{b}}$ should be determined by a remaining principle as a difference between the overall design cooling capacity $q_{0.10}$ for the whole process of cooling the ambient air to the target temperature $t_{a 2}=10^{\circ} \mathrm{C}$ and its basic stable ("laminar") load range $q_{0.10-15}$ for subcooling air from a threshold air temperature of about $15^{\circ} \mathrm{C}$ after ACh to $t_{a 2}=10^{\circ} \mathrm{C}: q_{0 . \mathrm{b}}=q_{0.10}-q_{0.10-15}$, where $q_{0.10-15}=q_{0.10}-$ $q_{0.15}$.

\section{Results}

The further development of the methodology of TIAC system designing involves distribution of the overall design cooling capacity between unstable ("turbulent") thermal load range for ambient air precooling in the boost high temperature stage of the air cooler (AC) by ACh and a stable ("laminarized") load range for further air subcooling to the target temperature in the low temperature stage by ECh (Fig. 2).
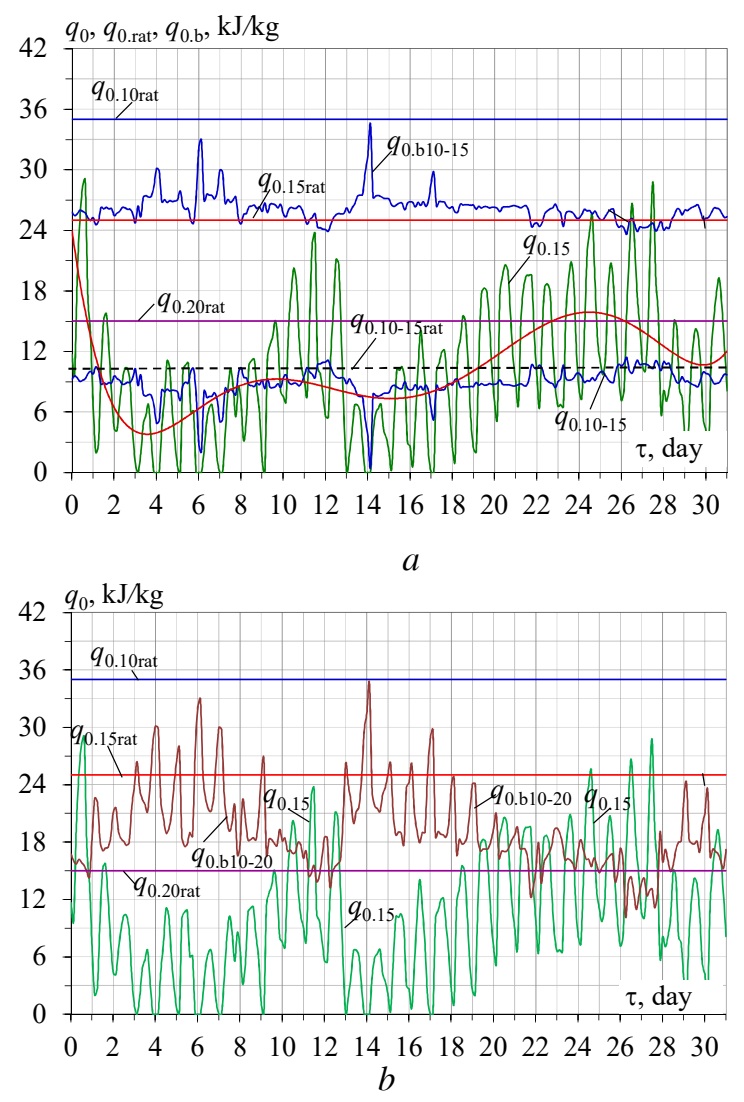

Fig.2. Current values of specific cooling capacities $q_{0.15}$ needed for cooling ambient air to $t_{a 2}=15^{\circ} \mathrm{C}$, rational cooling capacities $q_{0.10 \mathrm{rat}}, q_{0.15 \mathrm{rat}}$ and $q_{0.20 \mathrm{rat}}$ for $t_{a 2}=10,15$ and $20^{\circ} \mathrm{C}$, basic cooling capacities $q_{0.10-15}$ for cooling air from $t_{a 2}=15$ to $10^{\circ} \mathrm{C}$ and available residual boost part $q_{0 . b 10-}$ 15 for cooling air $t_{a 2}=15^{\circ} \mathrm{C}$ (a) and available residual boost part $q_{0 . b 10-20}$ for cooling air $t_{a 2}=20^{\circ} \mathrm{C}(\mathrm{b})$.

The values of specific cooling capacities $q_{0.15}$ needed for cooling ambient air to $t_{a 2}=15^{\circ} \mathrm{C}$, rational cooling capacities $q_{0.10 \mathrm{rat}}, q_{0.15 \mathrm{rat}}$ and $q_{0.20 \mathrm{rat}}$ for cooling ambient air to $t_{a 2}=10,15$ and $20^{\circ} \mathrm{C}$ accordingly, the basic cooling capacity as difference $q_{0.10-15}=q_{0.10}-q_{0.15}$, needed for cooling air from $t_{a 2}=15^{\circ} \mathrm{C}$ to $t_{a 2}=10^{\circ} \mathrm{C}$, available residual boost cooling capacities $q_{0.610-15}$ and $q_{0 . b 10-20}$ are calculated for climatic conditions in Voznesensk, Nikolaev region in July 2017 (Fig. 2).

As Fig. 2 shows, with cooling the ambient air to $t_{a 2}=15^{\circ} \mathrm{C}$ the fluctuations of the current thermal loads $q_{0.15}$ are gradual, that points to significant amount of an excessive cooling capacity in the temperate daily hours. At the same time, when air is cooled from $t_{a 2}=15^{\circ} \mathrm{C}$ to $t_{a 2}=10^{\circ} \mathrm{C}$, the fluctuations in the thermal load $q_{0.10-15}=$ $\mathrm{q}_{0.10}-\mathrm{q}_{0.15}$ are comparatively small. Thus, the temperature of cooled air $t_{a 2}=15{ }^{\circ} \mathrm{C}$ can be assumed as the threshold temperature for shearing the overall design thermal load on the TIAC system $q_{0.10 \text { rat }}$ into a comparatively stable ("laminarized") load range $\mathrm{q}_{0.10-}$ 15 and the boost unstable ("turbulent") range of ambient air precooling. So, the stable load value $q_{0.10-15}$ is chosen as basic stable part $q_{0.10-15}=q_{0.10}-q_{0.15}$ of a design cooling capacity $q_{0.10 \mathrm{rat}}=35 \mathrm{~kJ} / \mathrm{kg}$ (Fig. 1). Accordingly, the remaining part of $\mathrm{q}_{0.10 \text { rat }}$ is used for precooling the ambient air to the threshold temperature $t_{a 2}=15^{\circ} \mathrm{C}$ and determined as boost cooling capacity $q_{0 . \mathrm{b} 10-15 \mathrm{rat}}=35-$ $q_{0.10-15}$ (Fig. 2,b). The unstable $q_{0.15}$ thermal load range can be covered by ACh as well as the stable $\mathrm{q}_{0.10}$ 15 thermal load range - by ECh (Fig.3).

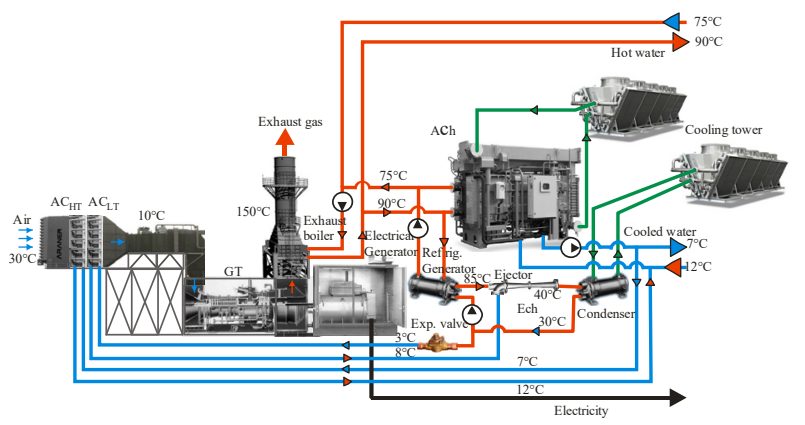

Fig. 3. A hybrid two-stage TIAC system in AECh: ACHт and $\mathrm{AC}_{\mathrm{LT}}$ - high and low temperature stages of air cooler; Exp. Valve - expansion valve.

As Fig. 2, a shows, the available boost cooling capacity $\mathrm{q}_{0 . \mathrm{b} 10-15 \text { rat }}$ generally covers current thermal loads $\mathrm{q}_{0.15}$ for precooling ambient air to $\mathrm{t}_{\mathrm{a} 2}=15^{\circ} \mathrm{C}$. Furthermore, even less available boost cooling capacity $\mathrm{q}_{0 . \mathrm{b} 10-20 \text { rat }}$ also covers the current loads $\mathrm{q}_{0.15}$ except quite short periods of daylight hours (Fig.2, b).

The next step in further enhancing the efficiency of TIAC systems and development of their design methodology is issued from the behavior of daily boost thermal load fluctuations. Proceeding from this, a new hypothesis is proposed to divide a design thermal load of unstable boost range $q_{0 . \mathrm{b} 10-15}$ in two parts as $q_{0 . \mathrm{b} 10-}$ ${ }_{15}=q_{0 . \mathrm{b} 10-20}+q_{0.15-20}$ or $q_{0.15 \mathrm{rat}}=q_{0.20 \mathrm{rat}}+q_{0.15-20}$ with daily accumulated excess as $q_{0.20 \mathrm{exc}}=q_{0 . \mathrm{b} 10-20}-q_{0.15}$ of design cooling capacity $q_{0.20 \text { rat }}$ over cooling needs $q_{0.15}$ for cooling air to $\mathrm{t}_{\mathrm{a} 2}=15^{\circ} \mathrm{C}$ in order to cover daily deficit $q_{0.20 \mathrm{def}}=q_{0.15}-q_{0 . \mathrm{b} 10-20}$ at peaked loads. On comparing current values of excess $q_{0.20 \mathrm{exc}}$ and deficit $q_{0.20 \mathrm{def}}$ as resulting refrigeration energy generated $\Sigma\left(q_{0.20} \tau\right)_{\mathrm{exc}}=\Sigma\left(q_{0 . \mathrm{b} 10-20 \mathrm{rat}}-q_{0.15}\right) \tau$ the hypothesis to reduce a design boost thermal load range $q_{0 . b 10-15}$ or $q_{0.15 \text { rat }}$ through using $q_{0.20 \text { rat }}$ to cover current cooling loads $q_{0.15}$, i.e. practically twice as compared with a design rational value $q_{0.15 \text { rat }}$ has been approved (Fig.4). 

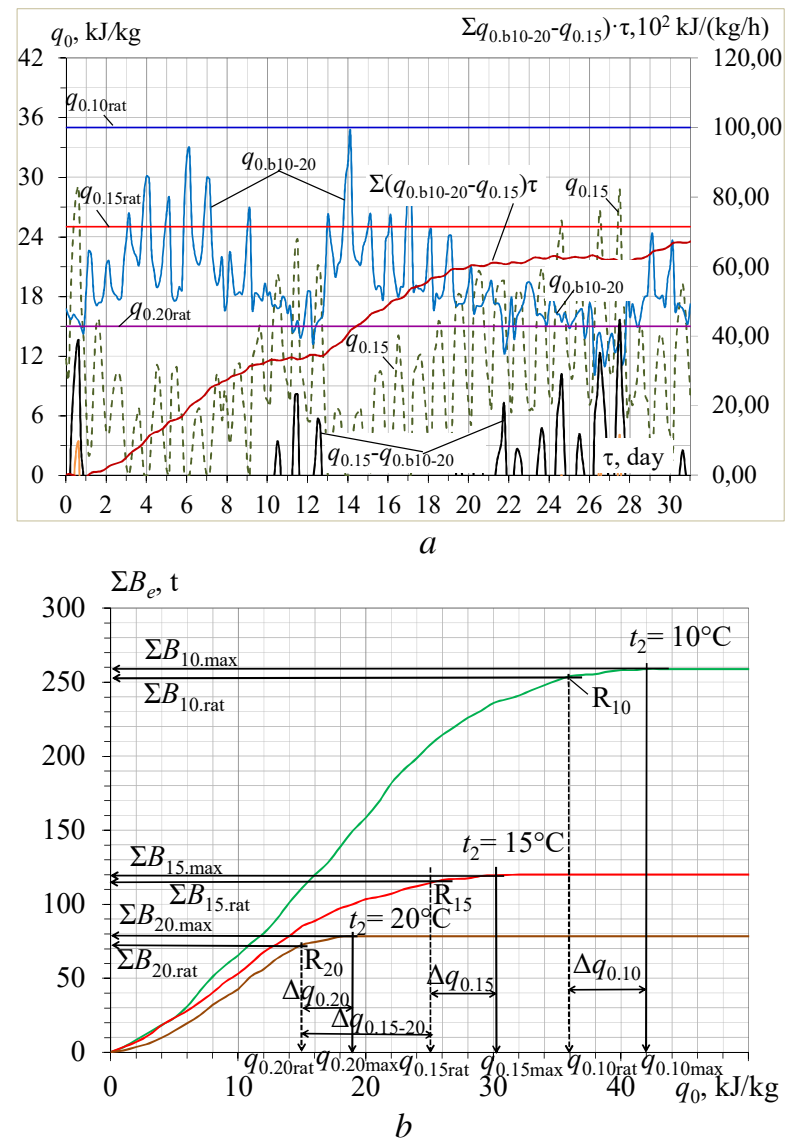

Fig. 4. Current values of thermal load $q_{0.15}$ for cooling ambient air to $t_{a 2}=15^{\circ} \mathrm{C}$, available specific boost cooling capacity $q_{0 . \mathrm{b} 10-20}$ for cooling air to $t_{a 2}=20^{\circ} \mathrm{C}$, deficit of design cooling capacity $q_{0.20 \mathrm{def}}=q_{0.15}-q_{0 . \mathrm{b} 10-20}$ for cooling air to $t_{a 2}=15^{\circ} \mathrm{C}$, summarized excess of available refrigeration energy $\Sigma\left(q_{0.20} \tau\right)_{\mathrm{exc}}=\Sigma\left(q_{0 . \mathrm{b} 10-20}-q_{0.15}\right) \tau$ over required $q_{0.15}$ for $t_{\mathrm{a} 2}=15{ }^{\circ} \mathrm{C}(\boldsymbol{b})$, annual fuel reduction $\sum B_{e}$ against specific design cooling capacity $\mathrm{q}_{0}$ for cooling ambient air to $\mathrm{t}_{\mathrm{a} 2}=10,15$ and $20^{\circ} \mathrm{C}: \sum \mathrm{B}_{10 ; 15 ; 20}-$ for $t_{\mathrm{a} 2}=10 ; 15$ and $20^{\circ} \mathrm{C}$; $\Delta q_{0.15-20}=q_{0.15 \mathrm{rat}}-q_{0.20 \mathrm{rat}} ; \quad \Delta q_{0.10,15,20}=q_{0.10,15,20 \max }-$ $q_{0.10,15,20 \text { rat }}$ p points $\mathrm{R}_{10,15,20}-q_{0.10,15,20 \text { rat }}$ and $\sum \mathrm{B}_{10,15,20 \text { rat. }}$

There are following correlations used:

reduction of design cooling capacity of ACh boost stage $\Delta q_{0.15-20}=q_{0.15 \text { rat }}-q_{0.20 \text { rat }}$;

reduction of design cooling capacity of AECh $\Delta q_{0.10}=q_{0.10 \max }-q_{0.10 \mathrm{rat}}$ and of ACh $\Delta q_{0.15,20}=$ $q_{0.15,20 \max }-q_{0.15,20 \mathrm{rat}}$;

current deficit of design cooling capacity $q_{0.20 \mathrm{def}}=q_{0.15}-q_{0 . \mathrm{b} 10-20}$;

summarized excess of available refrigeration energy $\Sigma\left(q_{0.20} \tau\right)_{\mathrm{exc}}=\Sigma\left(q_{0 . \mathrm{b} 10-20}-q_{0.15}\right) \tau$.

As Fig. 4, a testifies, the available boost cooling capacity $q_{0 . b 10-20}$ designed for cooling air to $t_{a 2}=20^{\circ} \mathrm{C}$ in general case is enough to cover the current cooling demands $q_{0.15}$ for deeper cooling air to $t_{a 2}=15{ }^{\circ} \mathrm{C}$. The current deficit of design cooling capacity $q_{0.20 \text { def }}=q_{0.15}-$ $q_{0 . \mathrm{b} 10-20}$ can be covered through using the daily accumulated excessive refrigeration energy. This statement is also approved by the continuously arising curve of the summarized excess of available design refrigeration energy over its current deficit $\Sigma\left(q_{0.20} \tau\right)_{\mathrm{exc}}=\Sigma\left(q_{0 . \mathrm{b} 10-20}-q_{0.15}\right) \tau$.

As Fig. 4, b shows, rational designing of TIAC systems provides decrease of installed cooling capacities of the chillers and TIAC systems in the whole by the values of $\Delta q_{0.10,15,20}$, i.e. by 15 to $20 \%$ compared with their maximum magnitudes $q_{0.10,15,20 \max }$, calculated according conventional practice of designing. The rational distribution of the installed cooling capacity of $\mathrm{ACh}$ enables to reduce a design boost load by the value $\Delta q_{0.15-20}=q_{0.15 \text { rat }}-q_{0.20 \text { rat }}$ (Fig. 4 , b), i.e. practically twice as compared with $q_{0.15 \text { rat }}$.

In temperate climatic conditions the application of rationally designed hybride two-stage TIAC systems with combined AECh enables to provide about 50\% higher annual fuel saving $\sum \mathrm{B}_{10 \text { rat }}$ at $q_{0.10 \text { rat }}$ as compared with $\sum \mathrm{B}_{15 \text { rat }}$ at $q_{0.10 \text { rat }}$ for ACh (Fig. 4,b) and can be considered as a novel prosperous trend in TIAC.

\section{Conclusions}

A novel trend in TIAC by two-stage air cooling in combined AECh is proposed to provide about 50\% higher annual fuel saving in temperate climatic conditions. An advanced methodology is developed to determine a rational design cooling capacities of TIAC systems that provides closed to maximum annual fuel saving and decrease of installed cooling capacity by 15 to $20 \%$ as compared with conventional TIAC designing practice.

A novel approach to designing the TIAC systems through rational distribution of the overall design cooling capacity between unstable ("turbulent") thermal load range for ambient air precooling in the boost high temperature stage of the air cooler by ACh and a stable ("laminarized") load range for further air subcooling to the target temperature in the low temperature stage by ECh. Such two-range distribution of the overall cooling capacity provides the favorable thermal loading conditions for operation of ECh at practically stable loads and realization of the advantages of ACh and ECh in combined AECh (high COP and deep air cooling).

Because of great uncertainty of unstable boost ("turbulent") load range magnitude its design value is determined by a remaining principle as a difference between the overall design cooling capacity for cooling the ambient air to the target temperature and its basic stable ("laminar") load range for subcooling air from a threshold temperature of the ambient air precooled in ACh. Issuing from daily fluctuations of excces and deficit of cooling capacity a new hypothesis to divide a design thermal load of unstable boost range in two load parts with daily accumulated excess of available design cooling capacity to cover daily deficit and to reduce a design boost load practically twice as result.

\section{References}

1. N. Farouk, L. Sheng, Q. Hayat, International Journal of Computer Science Issues, 10(1), 3, 439 (2013)

2. M. Ameri, S. H. Hejazi, Applied Thermal Engineering 24, 59 (2004)

3. B. Dawoud, Y.H. Zurigat, J. Bortmany, Applied Thermal Engineering 25, 1579 (2005) 
4. E. Trushliakov, A. Radchenko, S. Forduy, A. Zubarev, A. Hrych, Increasing the operation efficiency of air conditioning system for integrated power plant on the base of its monitoring, in Integrated Computer Technologies in Mechanical Engineering (ICTM 2019), AISC, 1113, pp. 351360 (2020)

5. E. Trushliakov, A. Radchenko, M. Radchenko, S. Kantor, O. Zielikov, The Efficiency of refrigeration capacity regulation in the ambient air conditioning system, in Advances in Design, Simulation and Manufacturing III (DSMIE 2020), LNME, pp. 343-353 (2020)

6. A. Radchenko, E. Trushliakov, V. Tkachenko, B. Portnoi, O. Prjadko, Improvement of the refrigeration capacity utilizing for the ambient air conditioning system, in Advanced Manufacturing Processes II, InterPartner 2020, LNME, pp. 714723 (2021)

7. A. Radchenko, A Stachel, S. Forduy, B. Portnoi, O. Rizun, Analysis of the efficiency of engine inlet air chilling unit with cooling towers, in Advances in Design, Simulation and Manufacturing III (DSMIE 2020), LNME, pp. 322-331 (2020)

8. S. Popli, P. Rodgers, V. Eveloy, Applied Thermal Engineering 50, 918 (2013)

9. D. Butrymowicz, J. Gagan, K. Śmierciew, M. Łukaszuk, A. Dudar, A. Pawluczuk, A. Łapiński, A. Kuryłowic, Investigations of prototype ejection refrigeration system driven by low grade heat, in E3S Web of Conferences 70, (2018)

10. A. Radchenko, E. Trushliakov, K. Kosowski, D. Mikielewicz, M. Radchenko, Energies 13, 6201 (2020)

11. J. Ortiga, J.C. Bruno, A. Coronas, Applied Thermal Engineering 50, 1536 (2013)

12. A. Khaliq, I. Dincer, P.B. Sharma, Journal of Energy Institute 83(2), 79 (2010)

13. P.A. Rodriguez-Aumente, M.C. RodriguezHidalgo, J.I. Nogueira, A. Lecuona, M.C. Venegas, Applied Thermal Engineering 50, 1496 (2013)

14. W. Kuczyński, H. Charun, Arch. Thermodyn. 32, $21(2011)$

15. D. Konovalov, H. Kobalava, M. Radchenko, I.C. Scurtu, R. Radchenko, Determination of hydraulic resistance of the aerothermopressor for gas turbine cyclic air cooling, in TE-RE-RD 2020, E3S Web of Conferences, 180, 01012 (2020)

16. V. Kornienko, M. Radchenko, R. Radchenko, D. Konovalov, A. Andreev, M. Pyrysunko, Improving the efficiency of heat recovery circuits of cogeneration plants with combustion of waterfuel emulsions. Thermal Science 25 (1 Part B), 791-800 (2021)

17. M. Radchenko, A. Radchenko, R. Radchenko, S. Kantor, D. Konovalov, V. Kornienko, Rational loads of turbine inlet air absorption-ejector cooling systems, Proceedings of the Institution of
Mechanical Engineers, Part A: Journal of Power and Energy (2021)

https://doi.org/10.1177/09576509211045455

18. R. Radchenko, M. Pyrysunko, A. Radchenko, A. Andreev, V. Kornienko, Ship engine intake air cooling by ejector chiller using recirculation gas heat, in Advanced Manufacturing Processes. InterPartner-2020, LNME, pp. 734-743 (2021)

19. R. Radchenko, M. Pyrysunko, V. Kornienko, I.-C. Scurtu, R. Patyk, Improving the ecological and energy efficiency of internal combustion engines by ejector chiller using recirculation gas heat, In Integrated Computer Technologies in Mechanical Engineering (ICTM 2020), LNNS, 188, pp. 531541 (2021)

20. M. Radchenko, D. Mikielewicz, V. Tkachenko, M. Klugmann, A. Andreev, Enhancement of the operation efficiency of the transport air conditioning system, in Advances in Design, Simulation and Manufacturing III (DSMIE 2020), LNME, pp. 332-342 (2020)

21. N. Radchenko, A. Radchenko, A. Tsoy, D. Mikielewicz, S. Kantor, V. Tkachenko, Improving the efficiency of railway conditioners in actual climatic conditions of operation, in AIP Conference Proceedings, 2285, 030072 (2020)

22. V. Kornienko, R. Radchenko, Ł. Bohdal, L. Kukiełka, S. Legutko, Investigation of condensing heating surfaces with reduced corrosion of boilers with water-fuel emulsion combustion, in Integrated Computer Technologies in Mechanical Engineering (ICTM 2020), LNNS, 188, pp. 300309 (2021)

23. L. Bohdal, L. Kukiełka, S. Legutko, R. Patyk, A.M. Radchenko, Materials 13, 3175 (2020)

24. M. Radchenko, R. Radchenko, V. Tkachenko, S. Kantor, E. Smolyanoy, Increasing the operation efficiency of railway air conditioning system on the base of its simulation along the route line, in Integrated Computer Technologies in Mechanical Engineering (ICTM 2019), AISC, 1113, pp. 461467 (2020)

25. E. Cardona, A. Piacentino, Applied Thermal Engineering 23, 15 p. (2003)

26. A. Canova, C. Cavallero, F. Freschi, L. Giaccone, M. Repetto, M. Tartaglia, IEEE Industry Applications Magazine 15, 62 (2009)

27. Z. Oktay, C. Coskun, I. Dincer, Energy 36(8), 4855 (2011)

28. S.B. Kalhori, H. Rabiei, Z. Mansoori, Energy Conv. Manag. 60, 106 (2012)

29. J.L. Forsyth, IGT International Liquefied Natural Gas Conference Proceedings 3, 1763 (2013)

30. Gas turbine electrical stations. Nikolaev: "ZoryaMashproject", 16 p. (2007) 